\title{
Reactions of $\mathrm{CH}_{3} \mathrm{OCH}_{2}^{+}$with Hydrocarbons and $\mathrm{O}, \mathrm{N}$, and $\mathrm{S}$ Compounds: Applications for Chemical Ionization in Selected Ion Flow Tube Studies
}

\author{
Paul F. Wilson, Daniel B. Milligan, Liew Wai Lam, Colin G. Freeman, \\ Michael Meot-Ner (Mautner), and Murray J. McEwan \\ Department of Chemistry, University of Canterbury, Christchurch, New Zealand
}

We report the results of a flowing afterglow ion source-selected ion flow tube study (FA-SIFT) of the reactions of the methoxymethyl cation, $\mathrm{CH}_{3} \mathrm{OCH}_{2}^{+}$. Rate coefficients and product branching ratios are reported for twenty nine reagent molecules including those that constitute the major ingredients of air, the hydrocarbons $\mathrm{CH}_{4}, \mathrm{C}_{2} \mathrm{H}_{6}, \mathrm{C}_{3} \mathrm{H}_{8}, \mathrm{n}-\mathrm{C}_{4} \mathrm{H}_{10}$, $\mathrm{C}_{2} \mathrm{H}_{2}, \mathrm{C}_{2} \mathrm{H}_{4}, \mathrm{C}_{3} \mathrm{H}_{4}$ (allene and propyne), $\mathrm{C}_{6} \mathrm{H}_{6}$, and the S-containing molecules $\mathrm{H}_{2} \mathrm{~S}, \mathrm{CH}_{3} \mathrm{SH}$, $\mathrm{C}_{2} \mathrm{H}_{5} \mathrm{SH},\left(\mathrm{CH}_{3}\right)_{2} \mathrm{SH}$, and $\left(\mathrm{C}_{2} \mathrm{H}_{5}\right)_{2} \mathrm{SH}$. In addition, we examined the reactions with the $\mathrm{N}$-containing molecules $\mathrm{NH}_{3}, \mathrm{CH}_{3} \mathrm{NH}_{2},\left(\mathrm{CH}_{3}\right)_{2} \mathrm{NH},\left(\mathrm{CH}_{3}\right)_{3} \mathrm{~N}$, pyrrole, pyridine as well as $\mathrm{CH}_{3} \mathrm{COCH}_{3}$. The results can be summarized under three general reaction types: Reaction at the $\mathrm{CH}_{3}$ carbon, reaction at the $\mathrm{CH}_{2}$ carbon, and association. The results also indicate that the methoxymethyl cation can be used as a chemical ionization source for the detection of trace levels of S-containing compounds in saturated hydrocarbons. (J Am Soc Mass Spectrom 2002, 13, 1028-1033) @ 2002 American Society for Mass Spectrometry

$\mathrm{T}$ The technique of chemical ionization was first applied to analyte identification when ion-molecule chemistry was in its infancy [1-3]. In recent times there has been a renewal of interest in the technique as new methods that utilize chemical ionization have been developed. These new methods have been used for detecting trace volatile organic compounds (VOCs) in air. Commercially available instruments now offer chemical ionization sources as "electronic nose" type add-ons [4,5]. Two recent methods that incorporate chemical ionization in combination with flow system methodology are proton transfer mass spectrometry as developed by Lindinger et al. [6] and selected ion flow tube mass spectrometry (SIFT-MS) developed by Smith and Spanel [7]. Most samples containing VOCs consist of only trace amounts of the VOCs in air. In order to detect those VOCs that may be present in concentrations as low as parts per billion (or even lower) by volume (ppb) in air, it is necessary that the chemical ionization precursor ion be "blind to" or unreactive with the bulk constituents of air (viz., $\mathrm{N}_{2}, \mathrm{O}_{2}$, $\mathrm{CO}_{2}, \mathrm{Ar}, \mathrm{H}_{2} \mathrm{O}$ ). In the SIFT-MS technique, the precursor ions that are generally chosen for chemical ionization are themselves "terminal" ions derived from air itself:

Published online July 24, 2002

Address reprint requests to Dr. M. J. McEwan, Department of Chemistry, University of Canterbury, Christchurch, New Zealand. E-mail: m.mcewan@chem.canterbury.ac.nz
They are $\mathrm{H}_{3} \mathrm{O}^{+}, \mathrm{O}_{2}^{+}$, or $\mathrm{NO}^{+}$[7]. These ions are, of course, convenient to use as sources for chemical ionization as they are readily produced from an air discharge. A second requirement for a precursor ion for trace amounts of VOCs in air is that it must be easily produced from a discharge in large ion densities. Reactant ion signals are typically required to be in excess of 100,000 counts per $\mathrm{s}$ at the particle multiplier detector at the downstream mass spectrometer for VOC detection in the ppb or ppt range.

It has been found that the three ion precursors mentioned above, $\mathrm{H}_{3} \mathrm{O}^{+}, \mathrm{O}_{2}^{+}$, and $\mathrm{NO}^{+}$, are not suitable for all gas mixtures. In this study we present data for the methoxymethyl cation, $\mathrm{CH}_{3} \mathrm{OCH}_{2}^{+}$, for consideration as a potential chemical ionization precursor for the detection of some VOCs in the presence of hydrocarbons.

The ion-molecule chemistry of $\mathrm{CH}_{3} \mathrm{OCH}_{2}^{+}$has been investigated previously and reported in several studies in the literature. The experimental techniques that have been used include ion cyclotron resonance (ICR) and flow tube studies. These studies [8-15] are referred to in the Results and Discussion section of this paper. The reason for the considerable interest in the chemistry of $\mathrm{CH}_{3} \mathrm{OCH}_{2}^{+}$is that it can react with reagents in two ways: Either at the $\mathrm{CH}_{3}$ carbon or at the $\mathrm{CH}_{2}$ carbon. Despite the considerable interest shown in the ion, the important reaction parameters such as the product 
channel ratios and rate coefficients have not been well characterized.

\section{Experimental}

The flowing afterglow ionization source combined with a selected ion flow drift tube (FA-SIFDT) used in our laboratory has been described previously [16]. In the present study, $\mathrm{CH}_{3} \mathrm{OCH}_{2}^{+}$ions are generated mainly via Penning ionization from $\mathrm{He}\left(2^{3} \mathrm{~S}\right)$ metastables reacting with dimethoxymethane, $\left(\mathrm{CH}_{3} \mathrm{O}\right)_{2} \mathrm{CH}_{2}$. Small amounts of dimethyoxymethane are added to a flowing helium afterglow produced via a microwave discharge. The $\mathrm{CH}_{3} \mathrm{OCH}_{2}^{+}$ion formed in the flowing afterglow source is mass-selected and drifted into the reaction flow tube (operating pressure 0.48 torr) via a series of ion lenses that focus the ion swarm onto the entrance aperture of a venturi orifice [16]. Signals of $\mathrm{CH}_{3} \mathrm{OCH}_{2}^{+}$in excess of 100,000 counts per second (cps) are readily achievable in our FA-SIFT instrument. A typical mass spectrum recorded by the downstream quadrupole mass filter after injection of $\mathrm{CH}_{3} \mathrm{OCH}_{2}^{+}$is 55,000 cps of $\mathrm{CH}_{3} \mathrm{OCH}_{2}^{+}$ and two small peaks corresponding to $\mathrm{CH}_{3}^{+}(<2000 \mathrm{cps})$ and $\mathrm{C}_{2} \mathrm{H}_{5}^{+}(<2000 \mathrm{cps})$. The two small peaks are the result of fragmentation of the primary ion during the injection process. As is usual with SIFT flow tube methodology, rate coefficients have an uncertainty of $\pm 15 \%$.

\section{Results and Discussion}

Several isomeric structures of the ion $\mathrm{C}_{2} \mathrm{H}_{5} \mathrm{O}^{+}$are known to be stable in the gas phase including $\mathrm{CH}_{3} \mathrm{CHOH}^{+}$(protonated acetaldehyde), $\mathrm{CH}_{2} \mathrm{CHOH}_{2}^{+}$ (protonated vinyl alcohol), $\mathrm{CH}_{2} \mathrm{OHCH}_{2}^{+}$(protonated oxirane), and the ion that is the subject of this study, $\mathrm{CH}_{3} \mathrm{OCH}_{2}^{+}$. We have explored the different reactivities of these isomeric ions in an earlier study [17] which demonstrated that the ion injected here using the method described previously had the $\mathrm{CH}_{3} \mathrm{OCH}_{2}^{+}$structure. We concentrate in this paper solely on the reactions of the methoxymethyl cation, $\mathrm{CH}_{3} \mathrm{OCH}_{2}^{+}$.

A number of earlier and mainly low pressure ion cyclotron resonance (ICR) investigations [8-15] have demonstrated that the methoxymethyl cation reacts with a nucleophile $\mathrm{M}$ in one of two ways:

$$
\begin{aligned}
\mathrm{CH}_{3} \mathrm{OCH}_{2}^{+}+\mathrm{M} & \rightarrow[\mathrm{M}+\mathrm{CH}]^{+}+\mathrm{CH}_{3} \mathrm{OH} \\
& \rightarrow\left[\mathrm{M}+\mathrm{CH}_{3}\right]^{+}+\mathrm{HCHO}
\end{aligned}
$$

At the higher pressures encountered within a flow tube, another product channel, that of association (eq 1c), may also be observed.

$$
\rightarrow\left[\mathrm{M}+\mathrm{CH}_{3} \mathrm{OCH}_{2}\right]^{+}
$$

Although the gas phase chemistry of the methoxym- ethyl cation has been well characterized in earlier ICR investigations $[8,10,11,13,23]$, the key parameters (rate coefficients and product distributions) required for the application of $\mathrm{CH}_{3} \mathrm{OCH}_{2}^{+}$as a chemical ionization agent in SIFT-MS are not well known. Indeed, the competition between bimolecular reaction and termolecular association (eq 1c) gives some insight into the stability of the ion-molecule complex. The greater reactant ion specificity of the flowing afterglow ion source used in this work [8] enables us to obtain more accurate product distributions than those reported in earlier studies. We report here accurate product distributions for flow tube studies for the first time.

We have summarised all the reactions investigated in this study in Table 1 and comment next on individual reactions.

Currently, the most comprehensive investigation of the reactivity of $\mathrm{CH}_{3} \mathrm{OCH}_{2}^{+}$is the flowing afterglow study by Freitas and O'Hair [15]. They present arguments for a mechanism whereby $\mathrm{CH}_{3} \mathrm{OCH}_{2}^{+}$acts as an ambident electrophile as it can react at the $\mathrm{CH}_{3}$ carbon via an $\mathrm{S}_{\mathrm{N}} 2$ methylation reaction (eq $1 \mathrm{~b}$ ) or at the $\mathrm{CH}_{2}$ carbon via an addition-elimination reaction (eq 1a). However, there are some significant differences between the flowing afterglow experimental results [15] and those of the present study (see Table 1). There are no reasons inherent to either method why these differences should occur as both use similar operating flow tube pressures between 0.36 and 0.48 torr.

Freitas and $\mathrm{O}^{\prime} \mathrm{Hair}$ generated $\mathrm{CH}_{3} \mathrm{OCH}_{2}^{+}$in their flowing afterglow by a two-step process. First they used electron impact on $\mathrm{N}_{2} \mathrm{O}$ to generate $\mathrm{NO}^{+}$. Dimethyl ether was subsequently added downstream from the ionization region and resulted in formation of the methoxymethyl cation via the reaction

$$
\begin{aligned}
\mathrm{NO}^{+}+\mathrm{CH}_{3} \mathrm{OCH}_{3} & \stackrel{0.95}{\longrightarrow} \mathrm{CH}_{3} \mathrm{OCH}_{2}^{+}+\mathrm{HNO} \\
& \stackrel{0.05}{\longrightarrow} \mathrm{NO}^{+} \mathrm{CH}_{3} \mathrm{OCH}_{3} \\
\mathrm{k} & =8.0 \times 10^{-10} \mathrm{~cm}^{3} \mathrm{~s}^{-1} .
\end{aligned}
$$

The rate coefficient represents the total disappearance of $\mathrm{NO}^{+}$and the numbers above each arrow refer to the measured branching ratios.

Our measured parameters for reaction (eq 2) are in good agreement with the results of Freitas and $\mathrm{O}^{\prime}$ Hair who reported a rate coefficient of $7 \times 10^{-10} \mathrm{~cm}^{3} \mathrm{~s}^{-1}$ [15].

In an attempt to resolve the differences in results between the measurements of Freitas and O'Hair [15] and this work, we examined several reactions of $\mathrm{N}_{2} \mathrm{O}^{+}$, which was also present in their flowing afterglow experiment. These included

$$
\begin{aligned}
\mathrm{N}_{2} \mathrm{O}+\mathrm{H}_{2} \mathrm{O} & \stackrel{0.90}{\longrightarrow} \mathrm{H}_{2} \mathrm{O}^{+}+\mathrm{N}_{2} \mathrm{O} \\
& \stackrel{0.10}{\longrightarrow} \mathrm{N}_{2} \mathrm{OH}^{+}+\mathrm{OH}
\end{aligned}
$$


Table 1. Reaction rate coefficients and product ratios for the reactions of $\mathrm{CH}_{3} \mathrm{OCH}_{2}^{+}$with the given reagent (numbers in parenthesis are previous measurements that have their origin indicated in the Table footnotes)

\begin{tabular}{|c|c|c|c|c|c|c|}
\hline Reagent & $\mathrm{k}_{\mathrm{Obs}}{ }^{\mathrm{a}}$ & $\mathrm{k}_{\text {Coll }}^{\mathrm{b}}$ & {$[\mathrm{M}+\mathrm{CH}]^{+}$} & {$\left[\mathrm{M}+\mathrm{CH}_{3}\right]^{+}$} & {$\left[\mathrm{M}+\mathrm{CH}_{3} \mathrm{OCH}_{2}\right]^{+}$} & Other \\
\hline $\mathrm{O}_{2}$ & $<0.0005$ & 0.68 & $n r^{\mathrm{c}}$ & & & \\
\hline $\mathrm{N}_{2}$ & $<0.0005$ & 0.74 & $\mathrm{nr}$ & & & \\
\hline $\mathrm{CO}$ & $<0.0005$ & 0.82 & $\mathrm{nr}$ & & & \\
\hline $\mathrm{CO}_{2}$ & $<0.0005$ & 0.81 & $\mathrm{nr}$ & & & \\
\hline $\mathrm{Ar}$ & $<0.0005$ & 0.66 & $\mathrm{nr}$ & & & \\
\hline $\mathrm{N}_{2} \mathrm{O}$ & $<0.0005$ & 0.90 & $\mathrm{nr}$ & & & \\
\hline $\mathrm{H}_{2} \mathrm{O}$ & $<0.0005(0.01)^{d}$ & 2.50 & $\mathrm{nr}$ & & $\operatorname{nr}(1.0)^{d}$ & \\
\hline $\mathrm{CH}_{4}$ & $<0.0005$ & 1.1 & $\mathrm{nr}$ & & & \\
\hline $\mathrm{C}_{2} \mathrm{H}_{6}$ & $<0.0005$ & 1.2 & $\mathrm{nr}$ & & & \\
\hline $\mathrm{C}_{3} \mathrm{H}_{8}$ & $<0.0005$ & 1.3 & $\mathrm{nr}$ & & & \\
\hline $\mathrm{n}-\mathrm{C}_{4} \mathrm{H}_{10}$ & $<0.0005$ & 1.3 & $\mathrm{nr}$ & & & \\
\hline $\mathrm{C}_{2} \mathrm{H}_{2}$ & $<0.0005$ & 1.1 & $\mathrm{nr}$ & & & \\
\hline $\mathrm{C}_{2} \mathrm{H}_{4}$ & $<0.0005$ & 1.2 & $\mathrm{nr}$ & & & \\
\hline $\mathrm{CH}_{3} \mathrm{C} \equiv \mathrm{CH}$ & 0.81 & 1.3 & 0.20 & 0.40 & 0.40 & \\
\hline $\mathrm{CH}_{2} \mathrm{CCH}_{2}$ & 0.37 & 1.3 & 0.10 & 0.70 & 0.20 & \\
\hline $\mathrm{C}_{6} \mathrm{H}_{6}$ & $0.49(1.9)^{\mathrm{d}}(0.5)^{\mathrm{e}}$ & 1.4 & $1.0(0.85)^{\mathrm{d}}(1.0)^{\mathrm{e}}$ & & $(0.15)^{d}$ & \\
\hline \multirow[t]{2}{*}{$\mathrm{NH}_{3}$} & $0.65(0.4)^{d}(0.59)^{f}$ & 2.3 & $0.95(0.70)^{d}(1.0)^{f}$ & $0.05(0.10)^{d}$ & $0.0(0.2)^{d}$ & \\
\hline & $(2.3)^{9}(0.43)^{n}$ & & & $(0.16)^{9}$ & & $(0.26)^{9}$ \\
\hline $\mathrm{ND}_{3}$ & 0.60 & 2.2 & 0.80 & 0.20 & & \\
\hline $\mathrm{CH}_{3} \mathrm{NH}_{2}$ & $\begin{array}{l}1.1(1.6)^{d}(1.50)^{e} \\
(0.94)^{h}\end{array}$ & 1.9 & $0.95(0.05)^{d}$ & $0.05(0.25)^{d}$ & $0.0(0.70)^{\mathrm{d}}$ & \\
\hline$\left(\mathrm{CH}_{3}\right)_{2} \mathrm{NH}$ & $0.94(1.2)^{\mathrm{d}}(0.37)^{\mathrm{e}}$ & 1.6 & $0.70(0.65)^{d}$ & $0.0(0.05)^{d}$ & $0.3(0.3)^{d}$ & \\
\hline$\left(\mathrm{CH}_{3}\right)_{3} \mathrm{~N}$ & $1.30(2.3)^{\mathrm{d}}(1.40)^{\mathrm{e}}$ & 1.5 & 0.0 & $0.0(0.05)^{d}$ & $0.70(0.95)^{d}$ & $0.30^{i}$ \\
\hline $\mathrm{C}_{4} \mathrm{H}_{5} \mathrm{~N}$ (pyrrole) & 2.0 & 2.1 & 0.45 & 0.0 & 0.55 & \\
\hline $\mathrm{C}_{5} \mathrm{H}_{5} \mathrm{~N}$ (pyridine) & $2.20(1.5)^{\mathrm{d}}$ & 2.5 & $0.0(0.15)^{d}$ & $0.05(0.15)^{d}$ & $0.95(0.70)^{d}$ & \\
\hline $\mathrm{CH}_{3} \mathrm{COCH}_{3}$ & $0.76(1.8)^{d}$ & 3.0 & & $0.2(0.1)^{d}$ & $0.80(0.9)^{d}$ & \\
\hline $\mathrm{H}_{2} \mathrm{~S}$ & $<0.0005(3.0)^{d}$ & 1.3 & $\mathrm{nr}(0.9)^{\mathrm{d}}$ & $\mathrm{nr}(0.05)^{\mathrm{d}}$ & $\mathrm{nr}(0.05)^{\mathrm{d}}$ & \\
\hline $\mathrm{CH}_{3} \mathrm{SH}$ & $0.31(0.6)^{d}$ & 1.9 & $0.05(0.65)^{d}$ & $0.0(0.05)^{d}$ & $0.95(0.30)^{d}$ & \\
\hline $\mathrm{C}_{2} \mathrm{H}_{5} \mathrm{SH}$ & $0.90(1.0)^{\mathrm{d}}$ & 2.0 & $0.85(0.30)^{d}$ & $0.0(0.25)^{d}$ & $0.15(0.45)^{\mathrm{d}}$ & \\
\hline$\left(\mathrm{CH}_{3}\right)_{2} \mathrm{~S}$ & $1.4(2.3)^{d}$ & 2.0 & $0.0(0.0)^{d}$ & $0.05(0.05)^{d}(1.0)^{j}$ & $0.95(0.95)^{d}$ & \\
\hline$\left(\mathrm{C}_{2} \mathrm{H}_{5}\right)_{2} \mathrm{~S}$ & 1.90 & 2.0 & & & 1.0 & \\
\hline
\end{tabular}

a Observed rate coefficient in units of $10^{-9} \mathrm{~cm}^{3} \mathrm{~s}^{-1}$.

${ }^{b}$ Calculated collision rate as described in reference [18] in units of $10^{-9} \mathrm{~cm}^{3} \mathrm{~s}^{-1}$.

cNo reaction observed.

${ }^{\mathrm{d}}$ Reference [15] ${ }^{\mathrm{e}}$ Reference [17] f Reference [14] (SIFT)

gReference [19]

${ }^{\mathrm{h}}$ Reference [14] (ICR) ${ }^{\text {TT }}$ The other product is $\left(\mathrm{CH}_{3}\right)_{2} \mathrm{NCH}_{2}^{+}+\mathrm{CH}_{3} \mathrm{OCH}_{3}$

${ }^{\mathrm{j} R e f e r e n c e ~[11], ~ l o w ~ p r e s s u r e ~ I C R ~ s t u d y . ~}$

$$
\begin{aligned}
& \mathrm{k}= 2.1 \times 10^{-9} \mathrm{~cm}^{3} \mathrm{~s}^{-1} . \\
& \mathrm{N}_{2} \mathrm{O}^{+}+\mathrm{H}_{2} \mathrm{~S} \stackrel{0.65}{\longrightarrow} \mathrm{H}_{2} \mathrm{~S}^{+}+\mathrm{N}_{2} \mathrm{O} \\
& \stackrel{0.35}{\longrightarrow} \mathrm{N}_{2} \mathrm{OH}^{+}+\mathrm{SH} \\
& \mathrm{k}=1.30 \times 10^{-9} \mathrm{~cm}^{3} \mathrm{~s}^{-1} .
\end{aligned}
$$

Water, at trace levels, is always present in the flow tube and therefore some $\mathrm{N}_{2} \mathrm{OH}^{+}$ions will be formed through reaction (eq $3 b$ ). It is unfortunate that $\mathrm{N}_{2} \mathrm{OH}^{+}$ is isobaric with $\mathrm{CH}_{3} \mathrm{OCH}_{2}^{+}$and its presence in the flow tube experiments of Freitas and $\mathrm{O}^{\prime}$ Hair will thus influence both the observed rate coefficients and the product distributions. A similar situation occurs with $\mathrm{H}_{2} \mathrm{~S}$ where the extent of $\mathrm{N}_{2} \mathrm{OH}^{+}$formation is even greater than with $\mathrm{H}_{2} \mathrm{O}$. We note that quite different results were found in our work for reactions of $\mathrm{CH}_{3} \mathrm{OCH}_{2}^{+}$with these reagents $\left(\mathrm{H}_{2} \mathrm{O}\right.$ and $\left.\mathrm{H}_{2} \mathrm{~S}\right)$ compared to those of Freitas and $\mathrm{O}^{\prime} \mathrm{Hair}$. Differences in the results for other reactions can be attributed to difficulties inherent to the flowing afterglow technique arising from the presence of multiple reactant ions. Freitas and $\mathrm{O}^{\prime} \mathrm{Hair}$ give error limits to their branching ratios of $\pm 50 \%$, whereas in the selected ion flow tube the error limits are typically $\pm 10 \%$ [8].

\section{Reactions of $\mathrm{CH}_{3} \mathrm{OCH}_{2}^{+}$with Hydrocarbons}

No reactions were observed with any of the alkanes studied in this work $\left(\mathrm{CH}_{4}, \mathrm{C}_{2} \mathrm{H}_{6}, \mathrm{C}_{3} \mathrm{H}_{8}, \mathrm{n}-\mathrm{C}_{4} \mathrm{H}_{10}\right)$ as well as ethene and ethyne, $\left(\mathrm{k}<5 \times 10^{-13} \mathrm{~cm}^{3} \mathrm{~s}^{-1}\right)$. Reactions were found to occur for propyne, allene and benzene (reaction exothermicities are indicated with the products in $\mathrm{kJ} \mathrm{mol}^{-1}$ based on a value for $\Delta_{\mathrm{f}} \mathrm{H}^{\circ}\left[\mathrm{CH}_{3} \mathrm{OCH}_{2}^{+}\right]$ $\left.=662 \mathrm{~kJ} \mathrm{~mol}^{-1}[9]\right)$ :

$$
\mathrm{CH}_{3} \mathrm{OCH}_{2}^{+}+\mathrm{CH}_{3} \equiv \mathrm{CH} \stackrel{0.20}{\longrightarrow} \mathrm{C}_{4} \mathrm{H}_{5}^{+}+\mathrm{CH}_{3} \mathrm{OH}+21
$$




$$
\begin{aligned}
& \stackrel{0.40}{\longrightarrow} \mathrm{C}_{4} \mathrm{H}_{7}^{+}+\mathrm{HCHO}+112 \\
& \stackrel{0.40}{\longrightarrow} \mathrm{CH}_{3} \mathrm{OCH}_{2} \cdot \mathrm{CH}_{3} \mathrm{CCH}^{+} \\
& \mathrm{k}=8.1 \times 10^{-10} \mathrm{~cm}^{3} \mathrm{~s}^{-1} . \\
& \mathrm{CH}_{3} \mathrm{OCH}_{2}^{+}+\mathrm{CH}_{2}=\mathrm{C}=\mathrm{CH}_{2} \stackrel{0.10}{\longrightarrow} \mathrm{C}_{4} \mathrm{H}_{5}^{+} \\
& +\mathrm{CH}_{3} \mathrm{OH}+25 \\
& \stackrel{0.70}{\longrightarrow} \mathrm{C}_{4} \mathrm{H}_{7}^{+}+\mathrm{HCHO}+116 \\
& \stackrel{0.20}{\longrightarrow} \mathrm{CH}_{3} \mathrm{COCH}_{2} \cdot \mathrm{CH}_{2} \mathrm{CCH}_{2}^{+} \\
& \mathrm{k}=3.7 \times 10^{-10} \mathrm{~cm}^{3} \mathrm{~s}^{-1} . \\
& \mathrm{CH}_{3} \mathrm{OCH}_{2}^{+}+\mathrm{C}_{6} \mathrm{H}_{6} \stackrel{1.0}{\longrightarrow} \mathrm{C}_{7} \mathrm{H}_{7}^{+}+\mathrm{CH}_{3} \mathrm{OH}+47 \\
& \mathrm{k}=4.9 \times 10^{-10} \mathrm{~cm}^{3} \mathrm{~s}^{-1}
\end{aligned}
$$

The reactions with propyne and allene are interesting in that the rate coefficients and product distributions for the isomers are quite different: More so than for most other ion-molecule reactions of these isomers [20]. The reaction of $\mathrm{CH}_{3} \mathrm{OCH}_{2}^{+}$with propyne is more than twice as fast as the reaction with allene and it is the association channel that is responsible for much of the difference. These results are consistent with the loss of $\mathrm{CH}_{3} \mathrm{OH}$ and $\mathrm{HCHO}$ from the reactions of $\mathrm{CH}_{3} \mathrm{OCH}_{2}^{+}$ with the hydrocarbons propene and but-2-ene that was observed in ICR studies [13].

The results for benzene are in excellent agreement with our earlier measurement of this reaction [9], but differ from the results reported by Freitas and O'Hair for the reasons discussed earlier. The reaction has a single channel with an addition-elimination mechanism after electrophilic attack on benzene by the $-\mathrm{CH}_{2}^{+}$ carbon, followed by $\mathrm{CH}_{3} \mathrm{OH}$ loss. The $\mathrm{C}_{7} \mathrm{H}_{7}^{+}$product ion is likely to have the benzyl structure as the amount of energy available is less than is necessary to cross the isomerization barrier of $301.5 \mathrm{~kJ} \mathrm{~mol}^{-1}$ leading to the tropylium structure [21]. There is also insufficient energy within the complex to allow rearrangement to the tropylium structure.

\section{Reactions of $\mathrm{CH}_{3} \mathrm{OCH}_{2}^{+}$with $\mathrm{N}$-Containing Compounds}

The reactions with amines and other molecules containing a nitrogen atom were all fast and all exhibited the addition-elimination reaction yielding $(\mathrm{M}+\mathrm{CH})^{+}+$ $\mathrm{CH}_{3} \mathrm{OH}$ as the major reaction channel.

The general mechanism for these reactions has been

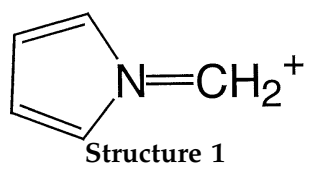

discussed previously by Pau et al. [10], Okada et al. [22], Caserio and Kim [23], and more recently by Freitas and $\mathrm{O}^{\prime}$ Hair [15]. Initial attack of the $-\mathrm{CH}_{2}^{+}$carbon at $\mathrm{N}$ followed by elimination of $\mathrm{CH}_{3} \mathrm{OH}$. Adduct formation is the main product channel observed for trimethylamine and also for the cyclic amines pyrrole and pyridine. The reaction with trimethylamine yields an additional product channel (eq 8a) that is unique within the range of reactant molecules studied.

$$
\begin{aligned}
\mathrm{CH}_{3} \mathrm{OCH}_{2}^{+}+\left(\mathrm{CH}_{3}\right)_{3} \mathrm{~N} & \stackrel{0.30}{\longrightarrow}\left(\mathrm{CH}_{3}\right)_{2} \mathrm{NCH}_{2}^{+} \\
& +\mathrm{CH}_{3} \mathrm{OCH}_{3} \\
& \stackrel{0.70}{\longrightarrow} \mathrm{CH}_{3} \mathrm{OCH}_{2} \cdot\left(\mathrm{CH}_{3}\right)_{3} \mathrm{~N}^{+} \\
\mathrm{k} & =1.30 \times 10^{-9} \mathrm{~cm}^{3} \mathrm{~s}^{-1}
\end{aligned}
$$

Although the neutral product is $\mathrm{CH}_{3} \mathrm{OCH}_{3}$ and not $\mathrm{CH}_{3} \mathrm{OH}$ from the addition/elimination reaction, the mechanism is the same. In this case, however, a $\mathrm{CH}_{3}$ group is transferred from trimethylamine to the $\mathrm{O}$ centre of $\mathrm{CH}_{3} \mathrm{OCH}_{2}^{+}$and not a proton as is the case with primary and secondary amines. In all cases the addition-elimination proceeds by the mechanism:

$$
\begin{aligned}
\mathrm{CH}_{3} \mathrm{OCH}_{2}^{+}+\mathrm{NR}_{3} & \rightarrow \mathrm{CH}_{3} \mathrm{OCH}_{2} \mathrm{NR}_{3}^{+} \\
& \rightarrow \mathrm{CH}_{2} \mathrm{NR}_{2}^{+}+\mathrm{CH}_{3} \mathrm{OR}
\end{aligned}
$$

Where one of the $\mathrm{R}$ groups is $\mathrm{H}$, this is transferred to the $\mathrm{CH}_{3} \mathrm{O}$ leaving group in preference to $\mathrm{CH}_{3}$ transfer which may have a higher energy barrier. However, with $\left(\mathrm{CH}_{3}\right)_{3} \mathrm{~N}$ the $\mathrm{H}$ transfer channel is not available and $\mathrm{CH}_{3}$ is transferred. The leaving group is likely to be $\mathrm{CH}_{3} \mathrm{OCH}_{3}$ instead of $\mathrm{CH}_{3} \mathrm{OH}$. The product ions are likely in all cases to be the N-alkylated imines $\left(\mathrm{R}_{2} \mathrm{~N}=\mathrm{CH}_{2}\right)^{+}$. These ions have no unprotonated neutral conjugated bases, but rather can be viewed as alkylation products of the $\mathrm{N}$-alkylated imines $\left(\mathrm{H}_{2} \mathrm{C}=\mathrm{NR}\right) \mathrm{R}^{+}$. It is interesting to note that addition-elimination also occurs with $\mathrm{c}-\mathrm{C}_{4} \mathrm{H}_{5} \mathrm{~N}$ (pyrrole) which behaves in a manner that is similar to the primary amines. The elimination step for pyrrole probably involves the nitrogen-bound hydrogen, $\mathrm{C}_{4} \mathrm{H}_{4} \mathrm{~N}-\mathrm{H}$, and the resulting product is possibly the protonated cyclic imine, Structure 1, (c$\left.\mathrm{C}_{4} \mathrm{H}_{4} \mathrm{~N}=\mathrm{CH}_{2}\right)^{+}$. On the other hand, in pyridine, where no $\mathrm{N}-\mathrm{H}$ hydrogen is available, addition-elimination is not observed.

The reaction with ammonia has been discussed in 
some detail by Okada et al. [22]. In an experiment with $\mathrm{ND}_{3}$, the distribution of $\mathrm{D}$ that we observed among the product ions is given by

$$
\begin{aligned}
& \mathrm{CH}_{3} \mathrm{OCH}_{2}^{+}+\mathrm{ND}_{3} \stackrel{0.80}{\longrightarrow} \mathrm{CH}_{2} \mathrm{ND}_{2}^{+}+\mathrm{CH}_{3} \mathrm{OD}+52 \\
& \stackrel{0.20}{\longrightarrow} \mathrm{CH}_{3} \mathrm{ND}_{3}^{+}+\mathrm{HCHO}+114 \\
& \mathrm{k}=6.0 \times 10^{-10} \mathrm{~cm}^{3} \mathrm{~s}^{-1}
\end{aligned}
$$

that is consistent with the addition-elimination mechanism for (eq 9a) and an $\mathrm{S}_{\mathrm{N}} 2$ mechanism for (eq 9b) as discussed in earlier investigations [17, 22].

Our observed rate coefficient and product distributions differ from those of Freitas and O'Hair [15], as discussed previously, but are consistent with earlier measurements from our laboratory [17].

\section{Reactions of $\mathrm{CH}_{3} \mathrm{OCH}_{2}^{+}$with $\mathrm{O}$ - and S-Containing Compounds}

The molecules examined in reaction with $\mathrm{CH}_{3} \mathrm{OCH}_{2}^{+}$ were $\mathrm{CH}_{3} \mathrm{COCH}_{3}, \mathrm{H}_{2} \mathrm{~S}, \mathrm{CH}_{3} \mathrm{SH}, \mathrm{C}_{2} \mathrm{H}_{5} \mathrm{SH},\left(\mathrm{CH}_{3}\right)_{2} \mathrm{~S}$, and $\left(\mathrm{C}_{2} \mathrm{H}_{5}\right)_{2} \mathrm{~S}$. For all reagents except $\mathrm{H}_{2} \mathrm{~S}(\mathrm{k}<5 \times$ $\left.10^{-13} \mathrm{~cm}^{3} \mathrm{~s}^{-1}\right)$, reactions were observed and the association channel was a major outcome of reaction in most cases. Freitas and $\mathrm{O}^{\prime}$ Hair note that whereas amines undergo addition-elimination reactions, most molecules containing $\mathrm{O}$ nucleophiles undergo methylation [15]. The reaction with acetone has been examined in several earlier low pressure ICR studies [11-13] in which the methyl transfer reaction was observed. Under low pressure ICR conditions $\left(<10^{-5}\right.$ torr) no adduct formation (eq 10b) was reported indicating that the metastable adduct ion lifetime is too short for collisional stabilization to be fast in the ICR. However, at the higher pressures of flow tubes, collisional stabilization is a major outcome of reaction as shown in reaction (eq 10).

$$
\begin{aligned}
\mathrm{CH}_{3} \mathrm{OCH}_{2}^{+}+\mathrm{CH}_{3} \mathrm{COCH}_{3} \stackrel{0.20}{\longrightarrow}\left(\mathrm{CH}_{3}\right)_{3} \mathrm{CO}^{+} \\
+\mathrm{HCHO}+76 \\
\stackrel{0.80}{\longrightarrow} \mathrm{CH}_{3} \mathrm{OCH}_{2} \cdot \mathrm{CH}_{3} \mathrm{COCH}_{3}^{+} \\
\mathrm{k}=7.6 \times 10^{-10} \mathrm{~cm}^{3} \mathrm{~s}^{-1}
\end{aligned}
$$

The reactions of $\mathrm{CH}_{3} \mathrm{OCH}_{2}^{+}$with the thiols $\mathrm{CH}_{3} \mathrm{SH}$ and $\mathrm{C}_{2} \mathrm{H}_{5} \mathrm{SH}$, exhibit an addition-elimination mechanism, giving $(\mathrm{M}+\mathrm{CH})^{+}+\mathrm{CH}_{3} \mathrm{OH}$, occurring in competition with adduct formation but in both cases the rate coefficient is substantially less than the collision rate coefficient (see Table 1).

$$
\begin{aligned}
& \mathrm{CH}_{3} \mathrm{OCH}_{2}^{+}+\mathrm{CH}_{3} \mathrm{SH} \stackrel{0.05}{\longrightarrow} \mathrm{CH}_{3} \mathrm{SCH}_{2}^{+}+\mathrm{CH}_{3} \mathrm{OH} \\
& \stackrel{0.95}{\longrightarrow} \mathrm{CH}_{3} \mathrm{OCH}_{2} \cdot \mathrm{CH}_{3} \mathrm{SH}^{+} \\
& \mathrm{k}=3.1 \times 10^{-10} \mathrm{~cm}^{3} \mathrm{~s}^{-1} \\
& \mathrm{CH}_{3} \mathrm{OCH}_{2}^{+}+\mathrm{C}_{2} \mathrm{H}_{5} \mathrm{SH} \stackrel{0.85}{\longrightarrow} \mathrm{C}_{2} \mathrm{H}_{5} \mathrm{SCH}_{2}^{+}+\mathrm{CH}_{3} \mathrm{OH} \\
& \stackrel{0.15}{\longrightarrow} \mathrm{CH}_{3} \mathrm{OCH}_{2} \cdot \mathrm{C}_{2} \mathrm{H}_{5} \mathrm{SH}^{+} \\
& \mathrm{k}=9.0 \times 10^{-10} \mathrm{~cm}^{3} \mathrm{~s}^{-1} .
\end{aligned}
$$

As the channel competing with adduct formation for both thiols is the addition-elimination reaction, it might be expected that the adduct ion structure has the form $\mathrm{RSCH}_{2} \mathrm{OHCH}_{3}^{+}$or, more likely, $\mathrm{RSHCH}_{2} \mathrm{OCH}_{3}^{+}$with the sulfur site of higher proton affinity being protonated [15].

On the other hand, the reactions with the sulfides $\left(\mathrm{CH}_{3}\right)_{2} \mathrm{~S}$ and $\left(\mathrm{C}_{2} \mathrm{H}_{5}\right)_{2} \mathrm{~S}$ seemed to favor $\mathrm{S}_{\mathrm{N}} 2$ substitution although, in both cases, adduct formation was the dominant channel.

$$
\mathrm{CH}_{3} \mathrm{OCH}_{2}^{+}+\left(\mathrm{CH}_{3}\right)_{2} \mathrm{~S} \stackrel{0.05}{\longrightarrow}\left(\mathrm{CH}_{3}\right)_{2} \mathrm{SCH}_{3}^{+}+\mathrm{HCHO}
$$

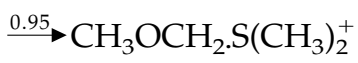

$$
\begin{aligned}
\mathrm{k}=1.4 \times 10^{-9} \mathrm{~cm}^{3} \mathrm{~s}^{-1} \\
\mathrm{CH}_{3} \mathrm{OCH}_{2}^{+}+\left(\mathrm{C}_{2} \mathrm{H}_{5}\right)_{2} \mathrm{~S} \stackrel{1.0}{\longrightarrow} \mathrm{CH}_{3} \mathrm{OCH}_{2} . \mathrm{S}_{\left(\mathrm{C}_{2} \mathrm{H}_{5}\right)_{2}^{+}} \\
\mathrm{k}=1.9 \times 10^{-9} \mathrm{~cm}^{3} \mathrm{~s}^{-1}
\end{aligned}
$$

If the $\mathrm{S}_{\mathrm{N}} 2$ mechanism is in fact operating in these two reactions, as is indicated by the products with dimethyl sulfide observed in (eq 13a) and in the low pressure ICR study of Kim and co-workers [10], then the adduct ion structure is likely to be $\mathrm{MCH}_{3} \mathrm{OCH}_{2}^{+}$where $\mathrm{M}=$ $\left(\mathrm{CH}_{3}\right)_{2} \mathrm{~S}$ or $\left(\mathrm{C}_{2} \mathrm{H}_{5}\right)_{2} \mathrm{~S}$. The fact that both reactions occur at rates close to the collision rate (see Table 1), implies that the collision complex lifetime is sufficiently long for collision stabilization to be effective for all (or almost all) complexes.

\section{Conclusion}

The methoxymethyl cation $\mathrm{CH}_{3} \mathrm{OCH}_{2}^{+}$can be injected into a flow tube from a flowing afterglow ion source in sufficient number density to produce an effective source for chemical ionization. The non-reaction of $\mathrm{CH}_{3} \mathrm{OCH}_{2}^{+}$with saturated hydrocarbons and its fast 
reaction with molecules containing sulfur provides an efficient way of quantifying thiols (mercaptans) and sulfides in hydrocarbons, whether present naturally or added as odorants. The data provided here enables the absolute detection of sulfur-containing molecules in mixtures of hydrocarbons down to 20 parts per billion using SIFT-MS methodology.

A final comment concerns the ease of adduct formation observed in many reactions of $\mathrm{CH}_{3} \mathrm{OCH}_{2}^{+}$at flow tube pressures. Association adducts were produced efficiently at pressures of $0.48(\mathrm{M}=\mathrm{He})$ in reactions of some amines, ketones, thiols, and sulfides. That many of these adducts were formed at or near the collision rate indicates that the ion-molecule collision complexes are sufficiently long-lived ( $\tau \gg 0.03 \mu$ s) to be stabilized by collision with the bath gas before extensive fragmentation can occur. In some reactions almost every complex formed is stabilized by collision and fragmentation does not occur to any significant extent. The adducts formed in these circumstances are strongly-bound covalent ions whose structures may be of the type $\mathrm{MCH}_{2} \mathrm{OHCH}_{3}^{+}(\mathrm{M}=$ nucleophile $-\mathrm{H})$ if an additionelimination mechanism dominates, or $\mathrm{MCH}_{3} \mathrm{OCH}_{2}^{+}$ $\left(\mathrm{M}=\right.$ nucleophile), when an $\mathrm{S}_{\mathrm{N}} 2$ mechanism dominates.

\section{Acknowledgments}

PFW acknowledges the award of a University of Canterbury Postdoctoral Fellowship. The authors thank the Marsden Fund for financial support.

\section{References}

1. Munson, M. S. B.; Field, F. H. J. Am. Chem. Soc. 1966, 88, $2621-2630$.
2. Munson, M. S. B.; Field, F. H. J. Am. Chem. Soc. 1966, 88, 4337-4345.

3. Munson, M. S. B.; Field, F. H. J. Am. Chem. Soc. 1967, 89, 1047-1052.

4. Linforth, R.; Preece, S. Technical Note 236, Micromass Ltd, 1998.

5. Adechy, M.; Shiess, V.; Squibb, A. Peak 2000, 1, 2-4.

6. Lindinger, W.; Hansel, A.; Jordan, A. Int. J. Mass Spectrom. Ion Proc. 1998, 173, 191-241.

7. Spanel, P.; Smith, D. Med. Biol. Eng. Comput. 1996, 34, 409-419.

8. Dunbar, R. C.; Shen, J.; Melby, E.; Olah, G. A. J. Am. Chem. Soc. 1973, 95, 7200-7202.

9. Van Doorn, R.; Nibbering, N. M. M. Org. Mass Spec. 1978, 13, 527-534.

10. Pau, J. K.; Kim, J. K.; Caserio, M.C. J. Am. Chem. Soc. 1978, 100, 3838-3846.

11. Kim, J. K.; Bonicamp, J.; Caserio, M. C. J. Org. Chem. 1981, 46, 4230-36.

12. Karpas, Z.; Meot-Ner, M. J. Phys. Chem. 1989, 93, 1859-1863.

13. Audier, H. E.; McMahon, T. B. J. Am. Chem. Soc. 1994, 116, 8294-8299.

14. Wilson, P. F.; McEwan, M. J.; Meot-Ner, M. Int. J. Mass Spectrom. Ion Proc. 1994, 132, 149-152.

15. Freitas, M. A.; O'Hair, R. A .J. Int. J. Mass Spectrom. Ion Proc. 1998, 175, 102-122.

16. Milligan, D. B.; Fairley, D. A.; Freeman, C. G.; McEwan, M. J. Int. J. Mass Spectrom. 2000, 202, 351-361.

17. Fairley, D. A.; Scott, G. B. I.; Freeman, C. G.; Maclagan, R. G. A. R.; McEwan, M. J. J. Chem. Soc. Faraday Trans. 1996, 92, 1305-1309.

18. Su, T.; Chesnavich, W. J. J. Chem. Phys. 1982, 76, 5183-5185.

19. Okada, S.; Abe, Y.; Taniguchi, S.; Yamabe, S. J. Am. Chem. Soc. 1987, 109, 295-300.

20. Anicich, V. G.; McEwan, M. J. Planet. Space Sci. 1997, 45, 897-921.

21. Smith, B. J.; Hall, N. E. Chem. Phys. Lett. 1997, 279, 165-171.

22. Okada, S.; Abe, Y.; Taniguchi, S.; Yamabe, S. J. Am. Chem. Soc. 1987, 109, 295-300.

23. Caserio, M. C.; Kim, J. K. J. Org. Chem. 1982, 47, 2940-2944. 